\title{
LOS DERECHOS CULTURALES DE LOS PUEBLOS INDÍGENAS EN LA JURISPRUDENCIA DE LA CORTE INTERAMERICANA DE DERECHOS HUMANOS*
}

\author{
Jaime Gajardo Falcón** \\ Universidad Diego Portales (Chile)
}

\section{RESUMEN}

El presente trabajo, en primer lugar, sistematiza la jurisprudencia de la Corte Interamericana de Derechos Humanos sobre los derechos culturales de los pueblos indígenas. En segundo lugar, analiza la incidencia que tiene la cultura de los pueblos indígenas en la interpretación de un conjunto de derechos asociados a la Convención Americana de Derechos Humanos. En tercer lugar, en el trabajo se propone una clasificación de la jurisprudencia que ha recaído sobre los derechos culturales de los pueblos indígenas. Finalmente, se exponen algunas conclusiones a las que se ha podido arribar del análisis jurisprudencial.

Palabras Clave: Corte Interamericana de Derechos Humanos, derechos culturales, multiculturalismo y pueblos indígenas.

\author{
CULTURAL RIGHTS IN THE JURISPRUDENCE \\ OF THE INTER-AMERICAN COURT OF HUMAN RIGHTS
}

\section{Abstract}

This paper, in the first place, systematizes the jurisprudence of the Inter-American Court of Human Rights on the cultural rights of indigenous peoples. Second, it analyzes the impact that the culture of indigenous peoples has on the interpretation of a set of rights associated with the American Convention on Human Rights. Third, the work proposes a classification of the jurisprudence on the cultural rights of indigenous peoples. Finally, some conclusions are presented.

KeYwords: Inter-American Court of Human Rights, cultural rights, multiculturalism and indigenous peoples. 


\section{INTRODUCCIÓN}

Los diferentes países que conforman el continente americano se encuentran integrados por diversas culturas y sus sociedades son multiculturales y multiétnicas. Así, la realidad cultural americana tiene un espesor cultural relevante que "colorea el mapa de la diversidad cultural del continente y tiene una función de argamasa: constituye a la vez un fenómeno de cohesión social y de apelación identitaria» ${ }^{1}$.

En ese sentido, la principal fuente de la diversidad cultural del continente americano viene dada por la presencia de diferentes pueblos y comunidades indígenas en prácticamente todos los Estados del continente. En la mayoría de los países latinoamericanos la población indígena se encuentra entre el 3\% y el 10\% de la población. Por su parte, México, Bolivia, Guatemala, Perú y Colombia reunen al 87\% de indígenas del continente. En ese sentido, destacan por tener una alta población indígena los siguientes países: Bolivia $(41 \%)^{2}$, Guatemala $(48 \%)^{3}$ y Perú $(25,8 \%)^{4}$. Así, en términos porcentuales se calcula que aproximadamente un $10 \%$ del total de la población de América Latina y el Caribe (50 millones de personas aproximadamente) se autoidentifican como parte de un pueblo indígena.

* Una versión preliminar del presente trabajo fue presentada en segunda sesión del Campus América que se celebró en el mes de julio de 2019 en la Universidad de La Laguna. Agradezco a quienes participaron de dicha sesión por sus valiosos comentarios, críticas y sugerencias. Este trabajo forma parte del proyecto FONDECYT de iniciación a la investigación número 11190460 titulado «Modelos de interpretación de los derechos fundamentales en contextos multiculturales y sus implicancias en los sistemas constitucionales», de la Agencia Nacional de Investigación y Desarrollo del Gobierno de Chile; y del proyecto de investigación «Jueces en Democracia. La filosofía política de la Corte Interamericana de Derechos Humanos», del Ministerio de Ciencia e Innovación de España (DER2016-79805-P, AEI/FEDER, UE).

** Abogado y magíster en Derecho, con mención en Derecho Público, Universidad de Chile. Máster en Gobernanza y Derechos Humanos, Universidad Autónoma de Madrid. Máster en Derecho Constitucional, Centro de Estudios Políticos y Constitucionales. Doctor en Derecho, Universidad Autónoma de Madrid. Profesor de la Cátedra de Derecho Constitucional, Universidad Diego Portales (Chile).

${ }^{1}$ Cfr. Subercaseaux, B., Nación y Cultura en América Latina. Diversidad cultural y Globalización, LOM Ediciones, Santiago, 2002, p. 16.

2 Según el Censo Nacional de 2012, 2,8 millones de personas mayores de 15 años, o el $41 \%$ de la población total, son de origen indígena. Los datos se pueden consultar en https://www. ine.gob.bo/index.php/censos-y-banco-de-datos/censos/.

${ }^{3}$ Datos del censo del año 2018, disponible en https://www.censopoblacion.gt/cuantossomos. Sin embargo, la Comisión Interamericana de Derechos Humanos ha dado cuenta de otras estadísticas que señalan que la población indígena que habita en Guatemala es del 60\%. Véase Informe CIDH, «Situación de los derechos humanos en Guatemala: Diversidad, desigualdad y exclusión», 2015, OEA/Ser.L/V/II.Doc. 43/15, p. 23.

${ }^{4}$ La caracterización estadística de la República de Perú, realizada por en el censo de 2017, señala que en Perú apróximadamente siete millones de personas (esto es, un 25,8\% de la población) se autoidentificó como parte de un pueblo indígena y un 3,6\% de la población como afroperuano. Los datos se pueden consultar en https://wwwl.inei.gob.pe/estadisticas/censos/. 
Debido a lo anterior, desde comienzos de la década de los ochenta, principalmente, en América Latina se viene desarrollando un fenómeno que se ha denominado la "emergencia indígena»" que ha implicado un resurgimiento de la cuestión indígena en el continente y grandes desafíos para los diferentes sistemas políticos y jurídicos. Para José Bengoa la demanda de los pueblos indígenas es profunda y radical; no sólo implica derechos para su grupo, sino que cuestiona los cimientos del Estado Nación en todo el continente ${ }^{6}$ y el modelo de desarrollo económico ligado a la explotación de los recursos naturales que se encuentran, principalmente, en los territorios que han ocupado ancestralmente los pueblos indígenas y sus comunidades ${ }^{7}$.

$\mathrm{La}$ «emergencia indígena», entre otras cosas, ha tenido un fuerte impacto en los sistemas normativos del continente, los que junto con suscribir y ratificar los principales instrumentos internacionales en materia indígena ${ }^{8}$ han constitucionalizado, con diferentes grados y profundidades, un conjunto de derechos específicos para los pueblos indígenas y sus miembros?.

De igual forma, el sistema interamericano de protección de los derechos humanos se ha destacado por dar una especial protección a los derechos de los pueblos indígenas, tanto en el trabajo de la Comisión Interamericana de Derechos Humanos (CIDH) como en la jurisprudencia de la Corte Interamericana de Derechos Humanos (Corte IDH). Así, en el presente trabajo me centraré en clasificar y analizar la jurisprudencia de la Corte IDH sobre los derechos culturales de los pueblos indígenas, la que ha sido abundante y referida a un gran conjunto de temas. Luego de analizar y clasificar la jurisprudencia señalada, finalizaré el trabajo con algunas conclusiones que se pueden obtener al respecto.

5 Véase Bengoa, J., La emergencia indígena en América Latina, Fondo de Cultura Económica, Santiago, 2007.

${ }^{6}$ Idem.

7 Al respecto, véase Gajardo, J., «El Derecho Humano a la Propiedad Comunal Indígena y el Modelo de Desarrollo en América Latina. Un Estudio de Casos», en Pele, A., Cittadino, G., Masbernat, P. y Modesto de Gasperín, R., Direitos Humanos e Neoliberalismo, Lumen Juris, Rio de Janiero, 2018, pp. 113-136. Asimismo, véase Martí i Puig, S., Wright, C., Aylwin, J. y Yáñez, N., Entre el desarrollo y el buen vivir, Catarata, Madrid, 2013.

${ }^{8}$ Sobre el derecho internacional de los pueblos indígenas, entre otros, véase 1) AnAYa, J., Los pueblos indigenas en el derecho internacional, Trotta, Madrid, 2005; 2) MACKAY, F., Los derechos de los pueblos indigenas en el sistema internacional, FIDH, Lima, 1999; 3) Aguilar, G., Dinámica internacional de la cuestión indígena, Librotecnia, Santiago, 2007.

${ }^{9}$ Sobre la constitucionalización de los derechos de los pueblos indígenas, entre otros, ver 1) Torbisco, N., «Derechos indígenas: reconocimiento y desafíos para la democracia constitucional y para los derechos humanos", en Hierro, L., Un conflicto de derechos: autonomía individual v. autonomía colectiva, Marcial Pons, Madrid, 2014, pp. 81-127; 2) YRIGoYen, R., «El horizonte del constitucionalismo pluralista: del multiculturalismo a la descolonización", en El derecho en América Latina. Un mapa para el pensamiento jurídico del siglo XXI, Siglo XXI, Buenos Aires 2011, pp. 139159; 3) Gajardo, J., "El reconocimiento constitucional de los pueblos indígenas en América Latina. Una revisión a los modelos y una propuesta de clasificación», en Gajardo, J. y ZúñIga, F., Constitucionalismo y procesos constituyentes. Vol. 2. Una revisión crítica al nuevo constitucionalismo latinoamericano, Thomson Reuters, Santiago, 2019, pp. 67-86. 


\section{JURISPRUDENCIA DE LA CORTE INTERAMERICANA DE DERECHOS HUMANOS SOBRE DERECHOS CULTURALES DE LOS PUEBLOS INDÍGENAS}

En este acápite abordaré la jurisprudencia de la Corte IDH sobre aspectos ligados a la cultura de fuente indígena. Los derechos culturales de los pueblos indígenas son una manifestación del principio de integridad cultural y consisten en el derecho de los pueblos indígenas y sus miembros de mantener y desarrollar libremente sus identidades culturales en coexistencia con otros sectores de la humanidad ${ }^{10}$.

Por su parte, los derechos culturales de los pueblos indígenas se encuentran recogidos, entre otros, tanto en el Convenio n. ${ }^{\circ} 169$ de la Organización Internacional del Trabajo (OIT) sobre Pueblos Indígenas y Tribales en Países Independientes como en la Declaración de las Naciones Unidas sobre los derechos de los pueblos indígenas y en la Declaración Americana sobre los derechos de los pueblos indígenas ${ }^{11}$.

Así, la jurisprudencia de la Corte IDH la agruparé en aquellos casos que dicen relación con aspectos culturales que se derivan del contenido del derecho a la vida ${ }^{12}$; del derecho a las garantías judiciales ${ }^{13}$; del derecho a la propiedad comunal ${ }^{14}$; del derecho a la familia ${ }^{15} \mathrm{y}$ de los derechos de la nińez indígena ${ }^{16}$; del derecho a libertad de pensamiento y de expresión ${ }^{17}$; y en cuanto a las medidas de reparación ${ }^{18}$.

${ }_{10} \mathrm{Al}$ respecto, véase Anaya, J., Los pueblos indigenas en el derecho internacional, Trotta, Madrid, 2005, pp. 179-202.

${ }^{11}$ Los derechos culturales de los pueblos indígenas y el principio de integridad cultural se encuentran reconocidos en los artículos 11 a 17 del Convenio n. ${ }^{\circ} 169$ de la OIT. En términos similares, tanto la Declaración de la ONU como la americana sobre derechos de los pueblos indígenas establecen los derechos culturales y el principio de integridad en el artículo 13 y siguientes, y en los artículos XXv y siguientes, de los respectivos instrumentos jurídicos internacionales.

12 En este punto revisaré la jurisprudencia de la Corte IDH recaída en los siguientes casos: a) caso Bámaca Velásquez con Guatemala (2000); b) caso Moiwana con Surinam (2005); c) caso Masacres de Río Negro con Guatemala (2012); d) caso Yakye Axa con Paraguay (2005); e) caso Sawhoyamaxa con Paraguay (2006); f) caso Xákmok Kásek con Paraguay (2010).

${ }_{13}$ En este punto revisaré la jurisprudencia de la Corte IDH recaída en los siguientes casos: a) caso Tiu Tojin con Guatemala (2008); b) caso Rosendo Cantú y otra con México (2010).

${ }^{14}$ En este punto revisaré la jurisprudencia de la Corte IDH recaída en los siguientes casos: a) caso Awas Tingi con Nicaragua (2000); b) caso Yakye Axa con Paraguay (2005); d) caso Sawhoyamaxa con Paraguay (2006); e) caso Xákmok Kásek con Paraguay (2010). Asimismo, se debe tener en consideración CIDH (2004). Informe caso Comunidades Indígenas Mayas del Distrito de Toledo (Belice).

${ }_{15}$ En este punto revisaré la jurisprudencia de la Corte IDH recaída en los siguientes casos: a) Chitay Nech y otro con Guatemala (2010); b) Norín Catrimán y otros con Chile (2014).

${ }^{16}$ En este punto revisaré la jurisprudencia de la Corte IDH recaída en los siguientes casos: a) caso Xákmok Kásek con Paraguay (2010); b) Chitay Nech y otro con Guatemala (2010); c) caso Rosendo Cantú y otra con México (2010); d) caso Masacres de Río Negro con Guatemala (2012).

${ }_{17}$ En este punto revisaré la jurisprudencia de la Corte IDH recaída en el caso López Álvarez con Honduras (2006).

${ }^{18}$ En este punto revisaré la jurisprudencia de la Corte IDH recaída en los siguientes casos: a) caso Aleoboetoe con Surinam (1993); b) caso Awas Tingi con Nicaragua (2000); c) caso Plan de Sánchez con Guatemala (2004); d) caso Moiwana con Surinam (2005). 
La jurisprudencia de la Corte IDH en este punto la dividiré en dos temáticas: 1) aquella que se relaciona con el derecho a una vida digna; 2 ) la que dice relación con aspectos culturales a considerar en el entierro y trato de un cadáver conforme a la cultura indígena ${ }^{19}$. Sobre el primer punto, esto es, la jurisprudencia que se relaciona con el derecho a una vida digna, podemos señalar los siguientes casos: a) caso Yakye Axa con Paraguay (2005); b) caso Sawhoyamaxa con Paraguay (2006); c) caso Xákmok Kásek con Paraguay (2010).

En el caso Yakye Axa con Paraguay (2005) la Corte IDH señaló que las comunidades indígenas habían visto vulnerado su derecho a la vida y vivían en condiciones de miseria extrema debido a la falta de tierra y acceso a sus recursos naturales. Para la Corte IDH, lo anterior se produce por el hecho de que las comunidades indígenas del Paraguay tienen un estrecho vínculo cultural con su tierra y, por ende, «el acceso a sus tierras ancestrales y al uso y disfrute de los recursos naturales que en ellas se encuentran están directamente vinculados con la obtención de alimento y el acceso a agua limpia $»^{20}$. Esta jurisprudencia se confirmó en el caso Sawhoyamaxa con Paraguay (2006) ${ }^{21}$ y fue enfatizada en el caso Xákmok Kásek con Paraguay (2010), ya que la Corte IDH consideró que «la ausencia de posibilidades de autoabastecimiento y auto-sostenibilidad de los miembros de la comunidad, de acuerdo a sus tradiciones ancestrales, los lleva a depender casi exclusivamente de las acciones estatales y verse obligados a vivir de una forma no solamente distinta a sus pautas culturales, sino en la miseria ${ }^{22}$. Como podemos apreciar, la Corte IDH no sólo caracteriza al pueblo indígena como un sujeto especial de protección, sino que vincula el derecho a la vida con el de propiedad para garantizar la supervivencia de la comunidad y su forma de vida, es decir, protege la diversidad cultural en sentido fuerte.

Otro aspecto en el que la jurisprudencia de la Corte IDH ha abordado aspectos culturales relacionados con el derecho a la vida en casos multiculturales es en aquellos relacionados con el entierro y trato de un cadáver conforme a la cultura indígena. En este punto los casos relevantes son: a) caso Bámaca Velásquez con Guatemala (2000); b) caso Moiwana con Surinam (2005); c) caso Masacres de Río Negro con Guatemala (2012).

La Corte IDH en el caso Bámaca Velásquez con Guatemala (2000), relativo a la desaparición forzada del miembro del Pueblo Indígena Maya Efraín Bámaca

19 Para un análisis completo de la jurisprudencia de la Corte IDH sobre el derecho a la vida, véase Ayala, C. y Rivero, M., "Artículo 4. Derecho a la Vida», en Steiner, CH. y Uribe, P. (eds.), Convención Americana sobre Derechos Humanos, KAS, Bogotá, 2014, pp. 112-130. Asimismo, véase Espejo, N. y Leiva, C., Digesto de jurisprudencia de la Corte Interamericana de derechos humanos, Thomson Reuters, Santiago, 2012, pp. 135-198.

${ }^{20}$ Cfr. SCrIDH (2005). Yakye Axa con Paraguay, párr. 167.

${ }^{21}$ Cfr. SCrIDH (2006). Sawhoyamaxa con Paraguay, párrs. 156-176.

${ }^{22}$ Cfr. SCrIDH (2010). Xákmok Kásek con Paraguay, párr. 214. 
Velásquez, consideró la existencia de un estrecho vínculo cultural para los miembros de dicho pueblo indígena y las honras fúnebres debido a que

esta Corte considera que el cuidado de los restos mortales de una persona es una forma de observancia del derecho a la dignidad humana. Asimismo, este Tribunal ha señalado que los restos mortales de una persona merecen ser tratados con respeto ante sus deudos, por la significación que tienen para éstos. El respeto a dichos restos, observado en todas las culturas, asume una significación muy especial en la cultura maya, etnia mam, a la cual pertenecía el señor Efraín Bámaca Velásquez. Ya la Corte ha reconocido la importancia de tener en cuenta determinados aspectos de las costumbres de los pueblos indígenas en América para los efectos de la aplicación de la Convención Americana sobre Derechos Humanos (Caso Mayagna (Sumo) Awas Tingni vs. Nicaragua). Como se ha reiterado en la audiencia pública sobre reparaciones en este caso, para la cultura maya, etnia mam las honras fúnebres aseguran la posibilidad de un reencuentro entre las generaciones de los vivos, la persona fallecida y los antepasados muertos. Así, el ciclo entre la vida y la muerte se cierra con esas ceremonias fúnebres, permitiendo «rendir respeto a Efraín, para tenerlo cerca y para devolverlo o llevarlo a convivir con los antepasados", así como para que las nuevas generaciones puedan compartir y aprender de lo que fue su vida, como es tradición en su cultura indígena ${ }^{23}$.

En el caso Moiwana con Surinam (2005) la Corte IDH realiza un razonamiento similar al del caso anterior, agregando que las afectaciones emocionales que sufrieron las víctimas de la comunidad indígena por el hecho de no poder honrar a sus muertos y enterrarlos según su cultura serían atentatorias no sólo con el derecho a la vida, sino también con el derecho a la integridad personal, consagrado en el artículo 5 de la Convención Americana de Derechos Humanos (CADH), por el sufrimiento que esto causaba en las víctimas (familiares) ${ }^{24}$.

Finalmente, en el caso Masacres de Río Negro con Guatemala (2012) la Corte IDH, junto con confirmar la jurisprudencia precitada vinculando las honras fúnebres con el derecho a la vida (artículo 4 de la CADH) y el derecho a la integridad personal (artículo 5 de la $\mathrm{CADH}$ ), también lo relaciona con el derecho a la libertad de conciencia y de religión, consagrado en el artículo 12 de la $\mathrm{CADH}^{25}$. Así, la Corte IDH señala que

... los miembros de la comunidad de Río Negro no pueden realizar sus rituales fúnebres por el hecho de que el Estado no ha localizado ni identificado a la mayor

${ }^{23}$ Cfr. SCrIDH (2002). Bámaca Velásquez con Guatemala, párr. 81.

${ }^{24}$ Cfr. SCrIDH (2005). Caso de la comunidad Moiwana con Surinam, párr. 100.

${ }_{25}$ Según Marco Huaco, si bien la Corte IDH había reconocido este derecho en la protección de las prácticas religiosas y el derecho a la identidad, hasta la fecha de su artículo esto no había sido aplicado en la parte resolutiva de las sentencias de la Corte IDH de manera explícita. Cfr. HuACO, M., "Artículo 12. Libertad de Conciencia y de Religión», en Steiner, CH. y Uribe, P. (eds.), Convención Americana sobre Derechos Humanos, KAS, Bogotá, 2014, p. 304. Asimismo, véase EsPejo y LeIVA, op. cit., p. 425. 
parte de los restos de personas supuestamente ejecutadas durante las masacres, y a que 17 personas se encuentran desaparecidas forzadamente. Pero, por otro lado, tampoco pueden realizar cualquier otro tipo de rituales pues los sitios sagrados a los cuales solían acudir se encuentran inundados a raíz de la construcción de la hidroeléctrica de Chixoy. Esta Corte ya ha señalado que «la relación especial de los pueblos indígenas con sus territorios ancestrales no estriba solamente en que constituyen su principal medio de subsistencia, sino un elemento integrante de su cosmovisión, religiosidad y, por ende, de su identidad o integridad cultural, el cual es un derecho fundamental y de naturaleza colectiva de las comunidades indígenas, que debe ser respetado en una sociedad multicultural, pluralista y democrática, como la de Guatemala ${ }^{26}$.

Con este último fallo la Corte IDH consolida una vanguardista jurisprudencia sobre el significado de los derechos de los pueblos indígenas en una sociedad multicultural en lo relacionado con sus derechos a la identidad cultural y religiosa. Como podemos apreciar, en este grupo de jurisprudencia para la Corte IDH el aspecto cultural es relevante no sólo para hacer una interpretación contextualizada y flexible de las normas de la CADH, sino también para conectar sus diferentes derechos (derecho a la vida, integridad personal y libertad de conciencia y de religión) ${ }^{27}$.

\section{II.II. Aspectos Culturales en las garantías JUdiciales}

La Corte IDH tiene una profusa jurisprudencia relacionada con el derecho a las garantías judiciales consagrado en el artículo 8 de la $\mathrm{CADH}^{28}$. En ese sentido, en materia multicultural indígena ha preceptuado la necesidad de que los miembros de los pueblos indígenas cuenten con un intérprete en sede jurisdiccional.

Así lo ha señalado en el caso Tiu Tojin con Guatemala (2008), relacionado con la desaparición forzada de Maria Tiu Tojin y su hija, quienes pertenecían al pueblo indígena maya. Para la Corte IDH, los familiares de la víctima tuvieron obstáculos para ejercer su derecho de acceso a la justicia debido a la falta de intérpretes para que la investigación de los hechos se hubiera realizado oportunamente. En ese sentido la Corte IDH señaló que

... para garantizar el acceso a la justicia de las víctimas -en tanto miembros del pueblo indígena Maya-y que la investigación de los hechos se realice con la debida

${ }^{26}$ Cfr. SCrIDH (2012). Caso Masacres de Río Negro con Guatemala, párr. 160.

27 Para una propuesta de interpretación de los derechos humanos en contextos multiculturales en el ámbito de los tribunales regionales de protección de los derechos humanos, véase GajARDo, J., Derechos humanos y multiculturalismo. Análisis comparado en la jurisprudencia de la Corte Interamericana y el Tribunal Europeo de Derechos Humanos, Thomson Reuters, Santiago, 2020.

${ }_{28} \mathrm{Al}$ respecto, véase IbÁÑez, J., "Artículo 8. Garantías Judiciales», en Steiner, CH. y Uribe, P. (eds.), Convención Americana sobre Derechos Humanos, KAS, Bogotá, 2014, pp. 207-254. Asimismo, véase Espejo y LeIva, op. cit., pp. 317-398. 
diligencia, sin obstáculos y sin discriminación, el Estado debe asegurar que aquellas puedan comprender y hacerse comprender en los procedimientos legales iniciados, facilitándoles intérpretes u otros medios eficaces para tal fin. Asimismo, el Estado deberá garantizar, en la medida de lo posible, que las víctimas del presente caso no tengan que hacer esfuerzos desmedidos o exagerados para acceder a los centros de administración de justicia encargados de la investigación del presente caso. Sin perjuicio de lo anterior, la Corte considera necesario ordenar al Estado el pago de una suma por concepto de gastos futuros, como una forma de garantizar que las víctimas puedan actuar en el proceso penal abierto ante la justicia ordinaria ${ }^{29}$.

Posteriormente, la Corte IDH resolvió en el caso Rosendo Cantú con México, en el que la víctima, que era miembro de la comunidad indígena me'paa y no hablaba español con fluidez, no pudo ejercer adecuadamente su derecho de acceso a la justicia cuando acudió a denunciar la violación sexual de la que había sido víctima por parte de militares mexicanos. En este caso, para la Corte IDH «no se proveyó a la señora Rosendo Cantú, quien al momento de los hechos no hablaba español con fluidez, de la asistencia de un intérprete, sino que debió ser asistida por su esposo, hecho que, a criterio de esta Corte no respeta su identidad cultural, y no resulta adecuado para asegurar la calidad del contenido de la declaración ni para proteger debidamente la confidencialidad de la denuncia. El Tribunal considera que resulta particularmente inapropiado que la señora Rosendo Cantú tuviera que recurrir a su marido para relatar los hechos de la violación sexual» ${ }^{30}$.

Este grupo de casos da cuenta de la importancia que tiene en la jurisprudencia de la Corte IDH la cultura indígena al momento de determinar el alcance de los derechos establecidos en la $\mathrm{CADH}$, que en este grupo de casos tenía relación con las garantías judiciales. Podemos apreciar que, para la Corte IDH, en sociedades multiculturales todos los derechos de la CADH se tienen que mirar bajo un prisma cultural y al momento de analizar un caso de tipo multicultural se deben tener en consideración las excepciones o especificaciones que se deben realizar en la interpretación de los derechos en juego, para lograr una plena efectividad de los derechos humanos.

${ }^{29}$ Cfr. SCrIDH (2008). Caso Tiu Tojin con Guatemala, párr. 100.

${ }^{30}$ Cfr. SCrIDH (2010). Caso Rosendo Cantú y otra con México, párr. 179. Comentando estos dos últimos casos, Oswaldo Ruiz y Gina Donoso señalan que no es clara la fuente normativa de la cual la Corte IDH ha derivado la obligación estatal según la cual para garantizar adecuadamente el acceso a la justicia se deba contar con un intérprete, ya que a su juicio la obligación contenida en el artículo 8 de la CADH no es fácil de desprender de dicho artículo. Al respecto, véase Ruiz, O. y Donoso, G., «Sección especial: Pueblos indígenas y la Corte Interamericana de Derechos Humanos. Fondo y reparaciones», en STEIner, CH. y URIBe, P. (eds.), Convención Americana sobre Derechos Humanos, KAS, Bogotá, 2014, p. 968. 
La jurisprudencia de la Corte IDH relativa a los derechos territoriales y la propiedad comunal indígena derivada del artículo 21 de la CADH es abundante y ha sido latamente revisada por diferentes autores ${ }^{31}$. Como en el presente trabajo me centro en los aspectos culturales de la jurisprudencia de la Corte IDH en el ámbito indígena, en este punto relevaré los fundamentos culturales que ha dado la Corte IDH para la protección de la propiedad comunitaria indígena.

Así, en un primer aspecto la Corte IDH ha fundamentado el derecho a la propiedad comunitaria por la «estrecha relación que los indígenas mantienen con la tierra», la que debe ser reconocida y comprendida como «la base fundamental de sus culturas, su vida espiritual, su integridad y su supervivencia económica. Para las comunidades indígenas la relación con la tierra no es meramente una cuestión de posesión y producción sino un elemento material y espiritual del que deben gozar plenamente, inclusive para preservar su legado cultural y transmitirlo a las generaciones futuras ${ }^{32}$.

Profundizando en el entendimiento del significado de cultura y su ligazón con la tierra y la propiedad comunitaria, la Corte IDH en el caso Yakye Axa señaló que

... la cultura de los miembros de las comunidades indígenas corresponde a una forma de vida particular de ser, ver y actuar en el mundo, constituido a partir de su estrecha relación con sus territorios tradicionales y los recursos que allí se encuentran, no sólo por ser estos su principal medio de subsistencia, sino además porque constituyen un elemento integrante de su cosmovisión, religiosidad y, por ende, de su identidad cultural ${ }^{33}$.

En el mismo sentido, para la Comisión Interamericana de Derechos Humanos $(\mathrm{CIDH})$ «la relación especial entre los pueblos indígenas y tribales y sus territorios significa que el uso y goce de la tierra y de sus recursos son componentes integrales de la supervivencia física y cultural de las comunidades indígenas y de la efectiva realización de sus derechos humanos en términos más generales» ${ }^{34}$.

Además, la $\mathrm{CIDH}$ ha señalado que dicha relación especial entre los pueblos indígenas y su territorio es fundamental para la integridad cultural de los pue-

${ }^{31} \mathrm{Al}$ respecto, entre otros, véase Russo, A. y Wences, I., «De los derechos de los "miembros de las comunidades" a los derechos de la "comunidad y sus miembros": la diversidad cultural y el reconocimiento de la propiedad colectiva de los pueblos indígenas en la Corte Interamericana de Derechos Humanos», en Santolaya, P., y Wences, I., La América de los Derechos, Centro de Estudios Políticos y Constitucionales, Madrid, 2016, pp. 281-326.

${ }^{32}$ Cfr. SCrIDH (2000). Caso Awas Tingi con Guatemala, párr. 149. Esto ha sido refrendado en los siguientes casos: a) caso Awas Tingi con Nicaragua (2000); b) caso Yakye Axa con Paraguay (2005); d) caso Sawhoyamaxa con Paraguay (2006); e) caso Xákmok Kásek con Paraguay (2010).

${ }_{33}$ Cfr. SCrIDH (2005). Caso Yakye Axa con Paraguay, párr. 135.

34 Cfr. CIDH (2010). Informe temático, pp. 21-22. 
blos indígenas, debido a «que los conceptos de familia y de religión se conectan íntimamente con el territorio tradicional, en donde los cementerios ancestrales, los lugares de significado e importancia religiosos y los patrones de parentesco se vinculan a la ocupación y uso de sus territorios físicos $»^{35}$. Así, para la CIDH la sociedad indígena se estructura en base a su relación profunda con la tierra, ya que la tierra constituye para los pueblos indígenas una condición de la seguridad individual y del enlace del grupo ${ }^{36}$.

Como podemos apreciar en la jurisprudencia sobre propiedad comunal indígena de la Corte IDH, la importancia cultural que tiene la relación de los pueblos indígenas con la tierra para la noción misma del significado de ser indígena y la constitución de sus comunidades no sólo es relevada por la Corte IDH al momento de interpretar el artículo 21 de la $\mathrm{CADH}$, sino que es la base para configurar un nuevo tipo de derecho humano a la propiedad en el caso de los pueblos indígenas, que tiene las características de ser un derecho de grupo y que se conecta con una serie de derechos protegidos en la CADH, tales como el derecho a la vida, la libertad de conciencia y religión y el derecho de protección a la familia.

La construcción teórica que realiza la Corte IDH en el caso del derecho a la propiedad comunal indígena amparado en el artículo 21 de la CADH y su fundamento en la importancia cultural que tiene la especial relación con la tierra en el caso de los pueblos indígenas da cuenta de la óptica con la que enfrenta los casos de tipo multicultual la Corte IDH, siendo esta la de una amplia protección del principio de integridad cultural. Además, en la resolución de este tipo de casos, podemos apreciar cómo la Corte IDH utiliza las herramientas prácticas que ha dejado el debate multicultural, tales como la inversión de la carga de la prueba, la interpretación contextualizada y la deferencia a la cultura indígena ${ }^{37}$.

\section{II.IV. Aspectos Culturales en El DERECHO DE PROTECCión A LA FAMilia y LA NIÑEZ}

El artículo 17 de la CADH consagra el derecho de protección a la familia, afirmando que esta es un elemento natural y fundamental de la sociedad y que debe ser protegida por el Estado. Tal como apunta Mary Beloff, el concepto de familia ha tenido un desarrollo en el derecho internacional de los derechos humanos, transitando desde concepciones tradicionales y restrictivas hacia nociones abiertas y plurales, adaptándose a las diversas circunstancias, contextos y realidades sociales ${ }^{38}$.

Lo anterior es especialmente significativo en sociedades multiculturales, siendo relevante que en la interpretación de «los múltiples sentidos de la institu-

35 Cfr. ibid., p. 22.

36 Idem.

37 Al respecto, véase Gajardo, J., op. cit., pp. 72-83.

38 Cfr. Beloff, M., "Artículo 17. Protección a la familia», en Steiner, CH. y Uribe, P. (eds.), Convención Americana sobre Derechos Humanos, KAS, Bogotá, 2014, p. 389. 
ción "familia" y asegurar su debida protección es fundamental tener en cuenta que la Corte IDH ha establecido que los tratados de derechos humanos son instrumentos vivos, cuya interpretación tiene que acompañar la evolución de los tiempos y las condiciones de vida actuales" ${ }^{39}$.

Esta diversidad del concepto y alcance de las «familias» en contextos multiculturales fue reconocida por la Corte IDH en el caso Chitay Nech y otros con Guatemala. En dicho caso, la Corte IDH amplió el concepto de «familia» y el de «convivencia familiar» en el contexto indígena, señalando que esta no se limita al núcleo familiar dado por el parentesco, sino que incluye a las distintas generaciones que la componen e incluso a la comunidad de la cual se forma parte ${ }^{40}$.

Para la Corte IDH el desplazamiento forzado de la familia Chitay fuera de su comunidad provocó una ruptura con su identidad cultural, afectando su vínculo con sus familiares, su idioma y su pasado ancestral, generando para el Estado responsabilidad internacional por vulneración al artículo 17 de la $\mathrm{CADH}^{41}$. Así, para la Corte IDH el deber de protección de la vida familiar implica acciones positivas de resguardo hacia todas las estructuras familiares, así como en una amplia y plural concepción de la familia ${ }^{42}$.

Por su parte, en el caso de los derechos de la niñez, el artículo 19 de la CADH señala que los niños tienen el derecho a las medidas de protección que se requieran por parte de su familia, de la sociedad y del Estado ${ }^{43}$. En ese sentido, cuando se trata de nińos de comunidades indígenas, para la Corte IDH los Estados tienen una obligación adicional, cuya fuente normativa se encuentra en el artículo 30 de la Convención de Derechos del Niño ${ }^{44}$, que dice relación con la promoción y protección del derecho de los niños indígenas a vivir de acuerdo con su propia cultura, religión e idioma ${ }^{45}$.

Así lo determinó la Corte IDH en el caso de la Comunidad Indígena Xákmok Kásek con Paraguay al señalar que

Con respecto a la identidad cultural de los niños nińas de comunidades indígenas, el Tribunal advierte que el artículo 30 de la Convención sobre los Derechos del

39 Idem. Asimismo, véase Espejo y Leiva, op. cit., pp. 477-480.

${ }^{40}$ Cfr. SCrIDH (2010). Caso Chitay Nech y otros con Guatemala, párr. 159. Asimismo, véase SCrIDH (2014). Caso Norín Catrimán y otros con Chile, párrs. 402-411.

${ }^{41}$ Cfr. ibid., párrs. 159-163.

${ }^{42}$ Cfr. Beloff, op. cit., p. 426.

43 Para un estudio amplio de los deberes del Estado en razón de este artículo de la $\mathrm{CADH}$, véase Beloff, M., "Artículo 19. Derechos del niño», en Steiner, CH. y Uribe, P. (eds.), Convención Americana sobre Derechos Humanos, KAS, Bogotá, 2014, p. 389. Asimismo, véase Espejo y LeIVA, op. cit., pp. 487-520.

${ }^{44}$ El artículo 30 de la Convención de Derechos del Niño señala: «En los Estados en que existan minorías étnicas, religiosas o lingüísticas o personas de origen indígena, no se negará a un nińo que pertenezca a tales minorías o que sea indígena el derecho que le corresponde, en común con los demás miembros de su grupo, a tener su propia vida cultural, a profesar y practicar su propia religión, o a emplear su propio idioma».

${ }^{45}$ Cfr. Ruiz y Donoso, op. cit., p. 994. 
Niño establece una obligación adicional y complementaria que dota de contenido al artículo 19 de la Convención Americana, y que consiste en la obligación de promover y proteger el derecho de los nińos indígenas a vivir de acuerdo con su propia cultura, su propia religión y su propio idioma ${ }^{46}$.

Lo anterior fue ratificado por la Corte IDH en los casos Chitay Nech y otros con Guatemala $(2010)^{47}$ y en el caso Masacres de Río Negro con Guatemala $(2012)^{48}$. En particular, la Corte IDH en el caso Masacres de Río Negro señala que

... esta Corte ha sostenido que el desarrollo del niño es un concepto holístico que abarca el desarrollo físico, mental, espiritual, moral, psicológico y social. Para el desarrollo pleno y armonioso de su personalidad, los niños indígenas, de acuerdo con su cosmovisión, preferiblemente requieren formarse y crecer dentro de su entorno natural y cultural, ya que poseen una identidad distintiva que los vincula con su tierra, cultura, religión, e idioma ${ }^{49}$.

Con los grupos de casos revisados previamente, podemos apreciar (nuevamente) que la Corte IDH realiza un interpretación de los derechos humanos sensible a los aspectos culturales y que busca la plena realización de los mismos realizando un escrutinio fuerte de la actividad estatal. Para la Corte IDH en los casos de tipo multicultural se debe tener en consideración el papel que juegan las especificidades culturales en la configuración y posterior aplicación de los derechos humanos consagrados en la CADH.

\section{II.v. Aspectos Culturales EN El DeReCho A LA Libertad De PENSAMiento y DE EXPRESIÓN}

Para la Corte IDH la libertad de pensamiento y de expresión son parte de la trilogía de libertades personales que constituyen el prerrequisito de los derechos de participación política y son fundamentales para posibilitar el sistema democrático $^{50}$. De esta forma, el artículo 13 de la CADH establece el derecho a la libertad de pensamiento y de expresión, en el que, según la Corte IDH, la expresión y difusión del pensamiento constituyen una dimensión del mismo ${ }^{51}$. Así, en sociedades

46 Cfr. SCrIDH (2010). Caso Comunidad Indígena Xákmok Kásek con Paraguay, párr. 261.

47 Véase SCrIDH (2010). Caso Chitay Nech y otros con Guatemala, párrs. 167-168.

48 Véase SCrIDH (2012). Caso Masacres de Río Negro con Guatemala, párrs. 142-150.

49 Cfr. SCrIDH (2012). Caso Masacres de Río Negro con Guatemala, párr. 144.

50 Al respecto, véase SCrIDH (2010). Caso Manuel Cepeda con Colombia, párrs. 168-179.

51 Para un estudio amplio del derecho a la libertad de pensamiento y expresión en el marco de la CADH, véase Bertoni, E. y Zelada, C., «Artículo 13. Libertad de pensamiento y de expresión", en Steiner, CH. y Uribe, P. (eds.), Convención Americana sobre Derechos Humanos, KAS, Bogotá, 2014, p. 389, pp. 320-342. Asimismo, véase Espejo y Leiva, op. cit., pp. 427-465. 
multiculturales de fuente indígena se podría catalogar esta dimensión como el derecho a usar la lengua propia ${ }^{52}$.

En ese sentido, la Corte IDH en el caso López Álvarez con Honduras (2006), en el que se denunciaba al director del Centro Penitenciario de prohibir a la población indígena (garífuna) del penal utilizar su idioma, señala que: «el artículo 13.1 consagra expresamente la libertad de difundir oralmente la información. La Corte considera que uno de los pilares de la libertad de expresión es precisamente el derecho a hablar, y que éste implica necesariamente el derecho de las personas a utilizar el idioma de su elección en la expresión de su pensamiento. La expresión y la difusión de pensamientos e ideas son indivisibles, de modo que una restricción de las posibilidades de divulgación representa directamente, y en la misma medida, un límite al derecho de expresarse libremente: ${ }^{53}$.

Para la Corte IDH, los Estados tienen la obligación de considerar las diferencias entre la población indígena y la mayoritaria, con el objeto de adecuar y proteger culturalmente a la indígena, tomando en consideración que el idioma de los mismos es uno de los principales elementos de su cultura e identidad, ya que garantiza la expresión, difusión y transmisión de su cultura. Así, cualquier interferencia o restricción de la misma afecta gravemente el derecho a la libertad de pensamiento y expresión consagrado en el artículo 13 de la $\mathrm{CADH}$ y que en contextos multiculturales se manifiesta en el derecho a usar la lengua propia ${ }^{54}$.

En este caso, la Corte IDH construye (a partir de la cultura) una protección externa (en el sentido de Kymlicka) ${ }^{55}$ a favor de la supervivencia cultural de los pueblos indígenas y la protección de su integridad cultural. Las protecciones externas a los grupos culturales es una de las vías que han planteado los teóricos del liberalismo multicultural para establecer derechos diferenciados a los grupos étnicos y culturales dada la relevancia que tendrían estos para la autonomía de sus miembros ${ }^{56}$. Recogiendo estos presupuestos teóricos, la Corte IDH construye una garantía de este tipo realizando una interpretación contextualizada y flexible del derecho a la libertad de pensamiento y expresión consagrado en el artículo 13 de la $\mathrm{CADH}$.

${ }^{2}$ Cfr. Ruiz y Donoso, op. cit., p. 970.

33 Cfr. SCrIDH (2006). Caso López Álvarez con Honduras, párr. 165.

${ }^{4}$ Cfr. SCrIDH (2006). Caso López Álvarez con Honduras, párrs. 171-173.

55 Véase Kyмlicka, W., Ciudadanía multicultural, Paidós, Barcelona, 1996.

56 Idem. 
La Corte IDH ha desarrollado ampliamente las modalidades de reparación, siendo uno de los aspectos novedosos de la jurisprudencia de la misma ${ }^{57}$. En ese sentido la cultura indígena ha sido fundamental en la jurisprudencia de la Corte IDH tanto para la determinación de los beneficiarios de las reparaciones como para la evaluación del daño inmaterial.

En cuanto al rol que ha jugado la cultura indígena para la determinación de los beneficiarios de las reparaciones, la Corte IDH en el caso Aloeboetoe con Surinam (1993) no aplicó las normas del derecho civil nacional para ello, sino que reconoció las costumbres del pueblo indígena. Así, para la determinación de los herederos de las víctimas interpretó, según la cultura y costumbre indígena, los términos de «hijos», "cónyuge» $\mathrm{y}$ «ascendientes»" ${ }^{58}$.

Asimismo, la cultura indígena ha jugado un rol relevante en la determinación del daño inmaterial. Así, en el caso Aloeboetoe con Surinam la Corte IDH amplió el concepto de víctima para la determinación del daño, ya que consideró que los miembros de la comunidad indígena constituían una familia en sentido amplio, por lo que el daño que se le causaba a uno se les producía a todos, ordenando el pago de una indemnización por cada una de las víctimas ${ }^{59}$.

57 Al respecto, véase NASH (2009), pp. 9-94. Para un estudio sobre las formas de reparación y peculiaridades que deben tener estas cuando se trata de víctimas indígenas, véase Ruiz y Donoso, op. cit., pp. 998-1024.

${ }^{58}$ Cfr. SCrIDH (2006). Caso Aloeboetoe y otros con Surinam, párrs. 60-66. Sin embargo, «[...] al referirse a los ascendientes, la Corte advirtió que no haría ninguna distinción de sexos, aun cuando ello sea contrario a la costumbre. Por ende, tomó como beneficiarios de las reparaciones a las esposas de los cimarrones fallecidos, a los hijos de éstos con cada una de sus esposas, y al padre y madre de los fallecidos, sin hacer distinciones basadas en el género. El Tribunal básicamente dio prioridad al derecho individual por sobre el derecho colectivo, sin explicar por qué la cultura de la tribu en este punto violentaba algún derecho humano y sin hacer algún juicio de ponderación que explique el motivo de la preferencia de un derecho (individual) por sobre otro (colectivo). Es de notar que los familiares de las víctimas o sus representantes legales no solicitaron a la Corte que desconociera la cultura de su grupo. El Tribunal, sin petición de por medio, decidió dar prevalencia al enfoque de género en lugar del cultural. Esto puede dar lugar a muchos debates, sin embargo, un argumento interesante es este contexto es el de Culberstone y Pouligny, quienes demuestran que los grupos locales retornan a la tradición para resolver conflictos, pero también reconocen que las innovaciones parten de la realidad de cada cultura, y que tomando y ajustando ideas desde el exterior y reconfigurando viejos conceptos a nuevas experiencias se planifican y ajustan las estrategias locales». $C f$ r. Ruiz y Donoso, op. cit., p. 1001.

59 Cfr. SCrIDH (2006). Caso Aloeboetoe y otros con Surinam, párr. 83. Asimismo, véase SCrIDH (2000). Caso Awas Tingi con Nicaragua, párr. 83; SCrIDH (2004). Caso Plan de Sánchez con Guatemala, párrs. 80-83. 


\section{CONCLUSIONES}

Como hemos podido apreciar, en los casos de tipo multicultural de fuente indígena la Corte IDH incorpora de manera fuerte en la interpretación de las normas de la $\mathrm{CADH}$ los aspectos culturales, construyendo entendimientos específicos de los derechos convencionales para dichos casos y evaluando la actividad estatal bajo dicho prisma, es decir, bajo una óptica de tipo multicultural. Que la Corte IDH incorpore de forma fuerte los derechos culturales de los pueblos indígenas significa que establece un deber estricto de los Estados en la protección de las diferentes expresiones culturales de los pueblos indígenas, siendo estas fundamentales para una adecuada protección de los derechos a través de los que se expresan.

En este sentido, de la revisión jurisprudencial se puede constatar que para la Corte IDH la cultura de los pueblos indígenas tiene un rol importante en la determinación del contenido: del derecho a la vida; del debido proceso; del derecho a la propiedad y su configuración como el de propiedad comunal indígena; en el derecho de protección a la familia; y en el derecho a la libertad de expresión. De esta forma, cuando un miembro de un pueblo indígena o un pueblo indígena como tal recurre ante el Sistema Interamericano de Protección de los Derechos Humanos, los órganos del sistema evalúan la actividad estatal y su conformidad a la $\mathrm{CADH}$ incorporando en la interpretación de los derechos en cuestión la cultura indígena y estableciendo un deber estricto de protección de la integridad cultural por parte de los Estados.

Además, en la jurisprudencia analizada se puede evidenciar que para la Corte IDH los pueblos indígenas son un grupo vulnerable y, por ende, la protección que les debe brindar se encuentra reforzada por ese hecho. Debido a lo anterior, los derechos culturales de los pueblos indígenas forman parte de la especial protección que se les otorga y sus especifidades culturales son contextualizadas en el marco de culturas hegemónicas que los desatienden, invisibilizan o, derechamente, los discriminan.

¿Cuál sería el límite de la protección a los derechos culturales de los pueblos indígenas? Por ahora, la protección que les ha brindado la Corte IDH da cuenta de un conjunto de interpretaciones de los derechos de la CADH dentro del marco de entendimientos deferentes con las prácticas culturales de los pueblos indígenas y con prácticas que vienen a complementar los derechos de la $\mathrm{CADH}$ que hemos revisado. Sin embargo, la Corte IDH no ha tenido que resolver casos en los que las prácticas culturales de los pueblos indígenas puedan entrar en colisión con el núcleo de alguno de los derechos humanos de la $\mathrm{CADH}$ o que una deferencia hacia ellos pueda implicar la vulneración de derechos de terceros. En ese sentido, en términos generales podríamos señalar que la protección que ha otorgado la Corte IDH viene a complementar y especificar los derechos de la $\mathrm{CADH}$, aunque será interesante apreciar en el futuro posibles límites a la protección de los derechos culturales de los pueblos indígenas cuando estos afecten el núcleo de los derechos de la $\mathrm{CADH}$ o su protección pueda implicar la vulneración de los derechos humanos de terceros.

Así, podemos concluir anotando que la Corte IDH ha dado una amplia protección a las personas indígenas y sus comunidades, otorgándole a la cultura indígena un papel relevante al momento de resolver los casos que han sido sometidos 
a su conocimiento y en ámbitos culturales tan variados como aquellos que tienen impacto en el contenido del derecho a la vida; del derecho a las garantías judiciales; del derecho a la propiedad comunal; del derecho a la familia y de los derechos de la niñez indígena; del derecho a libertad de pensamiento y de expresión; y en cuanto a las medidas de reparación.

ReCiBIDO: septiembre de 2020; ACEPTADO: diciembre de 2020 